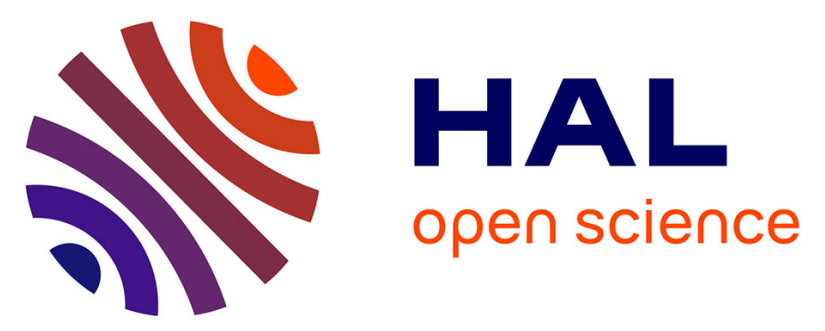

\title{
A DFT Study of R-X Bond Dissociation Enthalpies of Relevance to the Initiation Process of Atom Transfer Radical Polymerization
}

Malcolm Gillies, Krzysztof Matyjaszewski, Per-Ola Norrby, Tomislav Pintauer, Rinaldo Poli, Philippe Richard

\section{To cite this version:}

Malcolm Gillies, Krzysztof Matyjaszewski, Per-Ola Norrby, Tomislav Pintauer, Rinaldo Poli, et al.. A DFT Study of R-X Bond Dissociation Enthalpies of Relevance to the Initiation Process of Atom Transfer Radical Polymerization. Macromolecules, 2003, 36 (22), pp.8551-8559. 10.1021/ma0351672 . hal-03282391

\section{HAL Id: hal-03282391 \\ https://hal.science/hal-03282391}

Submitted on 19 Jul 2021

HAL is a multi-disciplinary open access archive for the deposit and dissemination of scientific research documents, whether they are published or not. The documents may come from teaching and research institutions in France or abroad, or from public or private research centers.
L'archive ouverte pluridisciplinaire HAL, est destinée au dépôt et à la diffusion de documents scientifiques de niveau recherche, publiés ou non, émanant des établissements d'enseignement et de recherche français ou étrangers, des laboratoires publics ou privés. 


\section{A DFT Study of R-X Bond Dissociation Enthalpies of Relevance to the Initiation Process of Atom Transfer Radical Polymerization}

Malcolm B. Gillies, ${ }^{\mathrm{a}}$ Krzysztof Matyjaszewski, ${ }^{* \mathrm{~b}}$ Per-Ola Norrby, ${ }^{\mathrm{a}}$ Tomislav Pintauer, ${ }^{\mathrm{b}}$ Rinaldo Poli, ${ }^{* c}$ Philippe Richard ${ }^{\mathrm{c}}$

${ }^{a}$ Department of Chemistry, Technical University of Denmark, Building 201, Kemitorvet, DK2800 Kgs. Lyngby, Denmark

${ }^{\mathrm{b}}$ Department of Chemistry, Carnegie Mellon University, 4400 Fifth Avenue, Pittsburgh, PA 15213, USA

${ }^{c}$ Laboratoire de Synthèse et d'Electrosynthèse Organométalliques, Faculté des Sciences "Gabriel", Université de Bourgogne, 6 Boulevard Gabriel, 21000 Dijon, France

Proofs to:

Rinaldo Poli

Tel: +33-380396881

Fax: +33-380393720

E-mail: poli@u-bourgogne.fr 


\section{Summary}

DFT calculations at the B3P86/6-31G** level have been carried out to derive the bond dissociation energies (BDE) and free energies for a number of $\mathrm{R}-\mathrm{X}$ systems $\left(\mathrm{X}=\mathrm{Cl}, \mathrm{Br}, \mathrm{I}, \mathrm{N}_{3}\right.$ and $\mathrm{S}_{2} \mathrm{CNMe}_{2}$ ) that have been or can potentially be used as initiators for atom transfer radical polymerization (ATRP). For selected systems, a conformational search was carried out for R$\mathrm{X}$ and $\mathrm{R}$ by using semi-empirical (PM3) and molecular mechanics (MM+ augmented with appropriately optimized parameters for the radical systems) methods. The MM+ technique is more suited to search for the most stable conformations. The computed energies are in good agreement with the experimentally available BDEs and reveal a small weakening effect caused by the substitution of an $\alpha-\mathrm{H}$ atom with a $\mathrm{CH}_{3}$ group. The free energies are used to derive relative equilibrium constant for the ATRP activation/deactivation process. These are compared with the equilibrium constants that have been determined from ATRP polymerization rates and from model studies of activation-deactivation-termination processes in the absence of monomer. These comparisons reveal the effectiveness of the DFT computed BDEs for predicting polymerization rates for new monomers in ATRP processes. 


\section{Introduction}

Atom transfer radical polymerization $(\mathrm{ATRP})^{1-3}$ is among the most efficient controlled/living radical polymerization processes. ${ }^{4-7}$ ATRP enables formation of well-defined polymers with controlled topology, composition and functionality. ${ }^{8-14}$ Mechanistically, ATRP is based on the inner sphere electron transfer process, which involves a reversible (pseudo)halogen transfer between macromolecular dormant species ( $\mathrm{R}-\mathrm{X})$ and a transition metal complex $\left(\mathrm{Mt}^{\mathrm{m}} / \mathrm{L}_{\mathrm{n}}\right)$ resulting in the formation of propagating radicals $\left(\mathrm{R}^{*}\right)$ and the metal complex in the higher oxidation state (e.g. X-Mt $\left.{ }^{\mathrm{m}+1} / \mathrm{L}_{\mathrm{n}}\right) .{ }^{15-19}$ Radicals form by activation $\left(\mathrm{k}_{\mathrm{act}}\right)$ and subsequently propagate $\left(\mathrm{k}_{\mathrm{p}}\right)$, reversibly deactivate $\left(\mathrm{k}_{\text {deact }}\right)$ but also terminate $\left(\mathrm{k}_{\mathrm{t}}\right)$, as shown in Scheme 1.

\section{Insert Scheme 1}

Understanding and control of the equilibrium and dynamics of the atom transfer process are the basic prerequisites for the control of ATRP. Thus, it is very important to correlate structures with reactivities of the involved reagents (transition metal complexes in both oxidation states, radicals and dormant species).

The overall equilibrium constant for ATRP ( $\mathrm{K}_{\text {ATRP }}$ in Scheme 2$)$ can be expressed as the product of the equilibrium constants for electron transfer between metal complexes $\left(\mathrm{K}_{\mathrm{ET}}\right)$, electron affinity of the halogen $\left(\mathrm{K}_{\mathrm{EA}}\right)$, for bond dissociation of the alkyl halide $\left(\mathrm{K}_{\mathrm{BD}}\right)$ and for the heterolytic cleavage of the $\mathrm{Mt}^{\mathrm{n}+1}-\mathrm{X}$ bond or "halogenophilicity" $\left(\mathrm{K}_{\mathrm{HP}}\right)$. Therefore, for a given alkyl halide R-X, the activity of the catalyst in the ATRP depends not only on the redox potential, but also on the halogenophilicity of the transition metal complex. For complexes that have similar halogenophilicities, the redox potential can be used as a measure of catalyst 
activity in the ATRP. This was demonstrated by the linear correlation between $\mathrm{K}_{\mathrm{ATRP}}$ and $\mathrm{E}_{1 / 2}$ for a series of $\mathrm{Cu}^{\mathrm{I}}$ complexes with nitrogen based ligands. ${ }^{20-22}$

\section{Insert Scheme 2}

Concurrently, $\mathrm{K}_{\text {ATRP }}$ under similar conditions using the same catalytic system (similar $\mathrm{K}_{\mathrm{ET}}, \mathrm{K}_{\mathrm{EA}}$ and $\mathrm{K}_{\mathrm{HP}}$ ) should depend only on the energetics of alkyl halides, i.e. $\mathrm{K}_{\mathrm{BD}}$. Thus, knowledge of $\mathrm{K}_{\mathrm{BD}}$ will enable estimates of $\mathrm{K}_{\mathrm{ATRP}}$ for new monomers. Unfortunately, there is only limited experimental data on BDEs of alkyl halides which resemble dormant species derived from vinyl monomers which can be used in ATRP. ${ }^{23}$ Therefore, we decided to use computational methods to estimate the BDE values for model alkyl (pseudo)halides (see Scheme 3) which mimic dormant species for ethylene (et), propylene (ipr), isobutene (tbu), styrene (sty), methylvinyl ether (ve), vinyl acetate (voac), methylvinyl ketone (vk), vinyl fluoride $(v f)$, vinylidene difluoride $(v d f)$, vinyl chloride $(v c l)$, vinyl bromide $(v b r)$, butadiene (all), acrylonitrile (an), $N, N$-dimethylacrylamide (dmam), methyl acrylate ( $\mathrm{ma}$ ) and methyl methacrylate ( $m m a)$. In addition we also included other chloride and bromide initiators that generate the tosyl (tos), benzyl (bz), dichloromethyl $(\mathrm{dcm})$ and trichloromethyl $(\mathrm{tcm})$ radicals. Although no controlled radical polymerization process is currently described for the $\alpha$-olefins and for some of the other systems that we have chosen (e.g. ve, vf), these systems were included to assess their propensity to produce radicals. In addition, thermodynamic data are available for these systems with which we can compare our computed values.

\section{Insert Scheme 3}

The calculated values of BDEs allow to better understand failures of some monomers to be polymerized by ATRP. They should also help to design better conditions for ATRP 
(temperature, concentrations) and set structural requirements for the potential catalysts to be applied. The calculated values correlate relatively well with experimental BDE data and also with the relative equilibrium constants from ATRP and similar methods. Thus, structural features of alkyl halides can now be correlated with their ATRP activities, and equilibrium constants can be roughly predicted for unreactive monomers. In fact, the range of activities is very large, covering more than 10 orders of magnitude. Thus, under comparable conditions using appropriate alkyl bromides as initiators, if ATRP of acrylonitrile would require 1 second to reach $90 \%$ conversion, methyl acrylate will need 2 hours, styrene 22 hours, vinyl acetate 30 years and ethylene 340000 years! Obviously different catalysts are needed for different monomers to account for the BDE differences.

\section{Computational details}

The conformations of selected $\mathrm{R}$ and $\mathrm{R}-\mathrm{X}$ molecules was explored by a molecular mechanics conformational search (MM+) and by an analogous search using semi-empirical quantum mechanical methods (PM3) by use of the Hyperchem program on a PC. The MM+ force field does not include parameters for hydrocarbon radicals. We determined the necessary 34 parameters, consistent with the existing ones, by a previously published automated least squares fitting procedure ${ }^{24}$ using DFT data for single minimized conformations of the compounds et, ipr, ma, mma and tbu. The reference data used for the parameter optimization consisted of the molecular internal coordinates and elements of the Hessian matrices for the five minima. Parameters were optimized in MacroModel using the MM3* force field ${ }^{25}$ and moved unchanged to MM+. RMS deviation of the force field minimized structures from the reference structures was $0.03 \AA$. As a single conformation was used for each compound, no relative energies were included in the parameterization (the 
parameters are included in the supplementary material). Charge bond increments were also fit to potential-derived charges. These were calculated separately at the BP86 geometries at the B3LYP/6-31G** level using the Jaguar program. Given that only a small quantity of reference data was used in the parameterization, and also that the parameter optimization was performed in a closely related but non-identical force field, the resulting parameters should be treated with caution and should only be used for finding reasonable low energy geometries to be subject to further refinement. The minimum energy conformations resulting from these searches were used as input for the DFT optimizations. For the other (simpler) molecules, reasonable starting geometry were built in a straightforward manner, or obtained by analogy with previously optimized geometries.

All DFT calculations were carried out using the B3P86 functional. ${ }^{26}$ The $6-31 \mathrm{G}^{* *}$ basis set was used for all $\mathrm{C}, \mathrm{H}, \mathrm{O}, \mathrm{N}, \mathrm{Cl}$ and $\mathrm{Br}$ atoms. Since the $\mathrm{I}$ atom is not included in the standard 6-31G** basis set, it was described by the LANL2DZdp basis, which includes a relativistic ECP and polarization $(d)$ and diffuse $(p)$ functions. ${ }^{27}$ This basis has the efficiency of a core-potential-containing basis set and is believe to provide the accuracy of an allelectron basis set such as 6-31G**. The $\mathrm{R}$ and $\mathrm{X}$ radicals were optimized with the spin unrestricted formalism; the spin contamination was found to be negligible in all cases (the mean value of the $S^{2}$ operator was always very close to the theoretical value of 0.75 ). All geometry optimizations were performed without symmetry constraints $\left(\mathrm{C}_{1}\right.$ symmetry). The nature of the resulting stationary points as energy minima was verified by a frequency analysis in each case. All energies were corrected for zero point vibrational energy and for thermal energy to obtain the bond dissociation enthalpies at $298 \mathrm{~K}$. A spin-orbit correction was also applied for $\mathrm{X}=\mathrm{Cl}, \mathrm{Br}$ and $\mathrm{I}$. A further entropy correction was applied to obtain the Gibbs Free Energy at 298 K. 
Single point energy calculations with an augmented basis set were carried out for the specific case of the $\mathrm{CH}_{3} \mathrm{CH}_{2} \mathrm{Cl} \mathrm{BDE}$ calculation. These involved basis sets that were essentially of triple-zeta quality and included double-zeta polarization on all atoms and diffuse $\mathrm{p}$ functions on $\mathrm{Cl}$ and $\mathrm{C}$ atoms. The $3 \mathrm{~s}$ and $3 \mathrm{p}$ orbitals of $\mathrm{Cl}$ were described by Hay and Wadt primitive basis sets ${ }^{28}$ augmented with a single diffuse s primitive, added even temperedly, and a p primitive. ${ }^{27}$ The d polarization primitive (alpha_d $=0.648$ ) from ref ${ }^{27}$ was doubly split (with a factor $=3$ ) and the resulting two functions were added, resulting in a primitive basis $(4 \mathrm{~s}, 4 \mathrm{p}, 2 \mathrm{~d})$ which was used uncontracted. $\mathrm{C}$ and $\mathrm{H}$ atoms were described by augmented Dunning triple-zeta ${ }^{29}$ sets denoted TZD2P. Compared to large atomic natural orbital (ANO) basis sets, these segmented TZD2P basis sets have been shown to be essentially converged with respect to one-particle basis set effects. ${ }^{29}$ All DFT calculations were carried out using Gaussian98. ${ }^{30}$

\section{Results and Discussion}

The Homolytic Bond Dissociation Enthalpies (BDEs) were calculated by difference from the energy of R-X and the energies of separated $\mathrm{R}$ and $\mathrm{X}$ radicals (lowest local minima), all calculations being carried out by the density functional theory approach, with the B3P86 functional. This choice was suggested by a recent study of R-O BDEs in $N$-alkoxyamines, where a performance comparison of several functionals with the experimentally available data revealed a better match for the B3P86 functional. ${ }^{31}$ Besides the various other corrections (see experimental part), an additional spin-orbit correction was also applied when $\mathrm{X}=\mathrm{Cl}, \mathrm{Br}$, and I, due to their atomic nature. In fact, the effect of the spin-orbit coupling term is not included in the DFT calculation, which consequently furnishes only the average energy of the ground state ${ }^{2} \mathrm{P}$ term. The extra stability of the real ground ${ }^{2} \mathrm{P}_{3 / 2}$ term is available from the literature $(\mathrm{Cl}, 0.8 ; \mathrm{Br}, 3.5 ; \mathrm{I}, 7.3 \mathrm{kcal} / \mathrm{mol}) .{ }^{32}$ For the other $\mathrm{X}$ and for the $\mathrm{R}$ and $\mathrm{R}-\mathrm{X}$ species, the spin- 
orbit contribution is quenched by the lower symmetry and no correction is necessary. All energetic results are collected in Table 1. All DFT, MM+ and PM3 optimized geometries are available in the form of Cartesian coordinates as supplementary material.

\section{Insert Table 1}

\section{(a) Free radicals}

All organic radicals led to stable minima with reasonable geometries. For the four radicals $m a, m m a, v k$ and $v o a c$, the existence of several conformations, leading to different energy minima, was investigated in detail by a combination of molecular mechanics $(\mathrm{MM}+)$, semiempirical (PM3) methods, in addition to the DFT calculations. For the ma, mma and voac systems there are two possible choices for the central $\mathrm{C}-\mathrm{O}-\mathrm{C}(\mathrm{O})-\mathrm{C}$ dihedral angle, either close to $0^{\circ}$ or close to $180^{\circ}$ (see Table 2). At all computational levels, the most stable conformation is that having this angle close to $180^{\circ}$ for the $m a$ and $m m a$ systems. For the voac radical, on the other hand, MM+ and DFT agree in giving the most stable conformation with a $180^{\circ}$ angle, whereas PM3 gives a slight edge in favor of the $0^{\circ}$ conformation. The energy difference between the two conformations is greatest at the DFT level. The MM+ analysis gives slightly smaller energy differences, whereas PM3 affords extremely small energy differences and, for the voac case, even an inversion of relative stability. This is in agreement with previous comparisons of conformational energy calculations. PM3 gives only moderate accuracy, whereas MM+ is based on MM2, which has been found to be one of the best methods available for determining conformational energies. ${ }^{33}$ For well-parameterized systems, the MM2/MM3 class of force fields has been shown to outperform both semiempirical and HF calculations, and even to rival DFT calculations. ${ }^{34}$ in press In the current case, the superficial determination of torsional parameters based only on the curvature at the 
minimum and not on dihedral drivers made us expect a lower accuracy, so the good agreement is gratifying. On the other hand, the relative $\mathrm{MM}+$ energies for the saturated halide systems rely on only standard parameters, so there the good results were expected. The most stable minimum for the $v k$ radical had essentially the same geometry at all three levels.

\section{Insert Table 2}

It is notable that the degree of pyramidalization at the carbon atoms bearing the unpaired electron varies as a function of the carbon substituents as shown in Table 3. The carbon is perfectly planar, as expected, when the unpaired electron can delocalize itself onto an adjacent unsaturation (i.e. sty, ma, mma, an, $v k$ and $a l l$ ). On the other hand, it becomes slightly pyramidal when adjacent to three saturated atoms, especially when at least one of them carries a lone pair (i.e. $v c l, v b r, \mathrm{dcm})$.

\section{Insert Table 3}

(b) Conformational analysis of the ma, mma, voac, vk and dmam chloride and bromide systems

The MM+ and PM3 conformational searches gave several optimized minima for each of these molecules. All methods agree as to the most stable arrangement for the central C-O$\mathrm{C}(\mathrm{O})-\mathrm{C}$ dihedral angle (close to $180^{\circ}$ like in the free radicals) for the $m a$ and $m m a$ systems. On the other hand, as already noted for the free radical, the voac system gives good accord between the MM+ and DFT results (the $180^{\circ}$ structure is more stable) and discrepancy with the PM3 results. The different methods afford slightly different values for the optimized X-CA-B dihedral angle ( $\theta$ angle, see definition in Scheme 4). All results are collected in Table 4. 


\section{Insert Scheme 4 and Table 4}

The best DFT geometries have, for all systems, $\theta$ values in a relatively narrow range between 46 and $90^{\circ}$. It can be observed that the MM+ optimizations afford geometries for the absolute minima that are, in most cases, closer to the best DFT geometries then those generated by the semiempirical PM3 method. Only for voac- $\mathrm{Cl}$ and $m a-\mathrm{Cl}$ does the $\mathrm{MM}+$ minimum differ substantially ( $\Delta \theta$ ca. $60^{\circ}$ and $40^{\circ}$, respectively) from that of the DFT minimum, whereas in all other cases this difference is at the most $22^{\circ}$ (for $m m a$-br). For each compound, the optimized minima at the two levels converted into each other when used as starting points for the optimization at the other level. There is, therefore, much better correlation between DFT and MM+ than between DFT and PM3, as expected from previous studies. ${ }^{33,34}$

\section{(c) Bond Dissociation Enthalpy, Entropy and Free Energy Trends}

All BDEs are listed in Table 1. The simplest system (et-Cl) was also calculated with a much larger basis set in addition to the more standard 6-31G** set, to check for the possible occurrence of Basis Set Superposition Errors (BSSE). The result is essentially indistinguishable relative to the smaller basis set, indicating that the inclusion of simple polarization functions in $6-31 \mathrm{G}^{* *}$ is sufficient to reduce the BSSE to negligible levels.

For each R, the energy decreases as $\mathrm{X}$ changes in the order $\mathrm{Cl}>\mathrm{Br}>\mathrm{N}_{3}>\mathrm{S}_{2} \mathrm{CNMe}_{2}>$ I, except for the $t b u$ system for which a reversal occurs (I $\left.>\mathrm{S}_{2} \mathrm{CNMe}_{2}\right)$. This is likely caused by steric effects, because the large encumbrance of the tert-butyl and N,Ndimethyldithiocarbamate groups may artificially weaken the $\mathrm{C}-\mathrm{S}$ bond. For all $\mathrm{R}$ groups, the difference between the BDEs of the chloride and the bromide decreases as the BDE decreases (from $11.06 \mathrm{kcal} / \mathrm{mole}$ for $\mathrm{R}=v d f$ to $6.37 \mathrm{kcal} / \mathrm{mole}$ for $\mathrm{R}=t o s$ ), in such a way that the 
$\mathrm{BDE}(\mathrm{R}-\mathrm{Cl}) / \mathrm{BDE}(\mathrm{R}-\mathrm{Br})$ ratio remains in the relatively narrow range between 1.12 and 1.18. On the other hand, the BDE difference between bromides and iodides unexpectedly increases along the same series (from $20.13 \mathrm{kcal} / \mathrm{mole}$ for $\mathrm{R}=$ et to $25.16 \mathrm{kcal} / \mathrm{mole}$ for $\mathrm{R}=m m a$ ). In terms of the variations of $\mathrm{BDE}$ as a function of $\mathrm{R}$, the order of decreasing energies for the chloride series $(e t>v d f>v f>v e>i p r>t b u>v o a c>v b r>v c l>d m a m>v k>d c m>m a>b z$ $>$ sty $>m m a>a n>a l l>t c m>t o s$ ) is almost the same as that for the bromide series. The most notable deviation is the relatively high BDE for the $v d f$ and $v f$ systems for chloride. The calculations show a slight but definite BDE decrease upon increasing the steric bulk of the R group, i.e. by adding a Me group on the $\mathrm{C}$ bearing the $\mathrm{X}$ substituent (see the $e t-i p r-t b u$, the $m a-m m a$, and the $b z-s t y$ series). This decrease is greater when $\mathrm{X}=\mathrm{I}$.

Table 1 also shows the calculated entropy and Gibbs' free energy changes associated with the R-X bond breaking process. The entropy change is in a relatively narrow range around $33 \mathrm{cal} \mathrm{K}^{-1} \mathrm{~mol}^{-1}$ for the halide systems (33.4 \pm 3.4 for all chlorides; $32.8 \pm 4.4$ for all bromides; $32.5 \pm 6.5$ for all iodides). This change, however, is systematically greater for the $i p r$ and $t b u$ systems and systematically lower for the $b z$ system. This can be attributed to the greater steric encumberance of the ipr and $t b u$ groups and to the achievement of a higher planar symmetry for the $b z$ radical. Stronger van der Waals repulsive interactions in the R-X compound are expected to restrict some of the vibrational modes to a greater extent than in the separate $\mathrm{R}$ and $\mathrm{X}$ groups, thereby artificially reducing the entropy of $\mathrm{R}-\mathrm{X}$ relative to the separate $\mathrm{R}$ and $\mathrm{X}$ fragments. By removing the $i p r, t b u$ and $b z \mathrm{R}$ groups from the statistics, the averages for all chloride, bromide and iodide systems have much lower standard deviations (33.3 $\pm 1.2,32.8 \pm 1.3$ and $32.0 \pm 0.7$, respectively). The slight decrease of $\Delta \mathrm{S}^{0}{ }_{298}$, for each $\mathrm{R}$, on going from $\mathrm{Cl}$ through $\mathrm{Br}$ to $\mathrm{I}$, can be attributed to smaller van der Waals repulsive interactions for the heavier halides. Thus, the size increase of the halogen atom is more than compensated by the increase of the R-X distance on going from the lighter to the heavier 
halogen. The azide series and the dithiocarbamate series show similar entropy changes (38$39 \mathrm{cal} \mathrm{K}^{-1} \mathrm{~mol}^{-1}$ for et, sty and $m a ; 42-46 \mathrm{cal} \mathrm{K}^{-1} \mathrm{~mol}^{-1}$ for ipr and $t b u$ ), greater than those of the halide systems.

The combination of the calculated $\Delta \mathrm{H}^{0}{ }_{298}$ and $\mathrm{T} \Delta \mathrm{S}^{0}{ }_{298}$ terms provides the Gibbs' free energies that are also listed in Table 1. The entropy contributions yield $\Delta \mathrm{G}^{0}{ }_{298}$ that are lower than the corresponding $\Delta \mathrm{H}^{0} 298$ by ca. $10 \mathrm{kcal} \mathrm{mol}^{-1}$, slightly more for the ipr and $t b u$ systems and for the azide and dithiocarbamate series.

\section{(d) Comparison with Experimentally Determined Bond Strengths and with Previous}

\section{Calculations}

As stated in the introduction, experimentally determined BDEs for $\mathrm{C}-\mathrm{X}$ bonds are rather limited and they are usually restricted to simple compounds. Thus, no values for several of the interesting initiators used in ATRP are available. The "Handbook of Bond Dissociation Energies in Organic Compounds" 23 collects most of the available data. Those that are relevant to our calculations are shown in Table 1. It must be pointed out, however, that the values have been determined by several different methods, including calorimetry, electron capture detection, shock wave, halogenation, photolysis, electrochemistry, infrared chemoluminescence and various derivations. The approximations used in the different methods may introduce systematic errors and yield values in excess or defect. For some of the compounds, in fact, the scatter of the experimental data is quite large (e.g. see ipr-Br and $d c m-\mathrm{Cl})$.

Table 1 shows that, by and large, the computed BDEs are quite close to the reported experimental values. This is especially true for the saturated halogenated hydrocarbons et-X, $i p r-\mathrm{X}, t b u-\mathrm{X}, v c l-\mathrm{X}$, and $v b r-\mathrm{X}$. We note, however, two interesting discrepancies. The experimentally determined values are essentially invariant upon addition of a methyl group on 
the $\mathrm{C}$ atom where the $\mathrm{X}$ group is bonded. On the other hand, a definite weakening is calculated by DFT (especially on going from $m a$ to mma, vide supra). In many cases, the large standard deviations and the scatter between the experimental values obtained by different methods may hide real trends. ${ }^{23}$ An example is provided by $\mathrm{Cl}-\mathrm{CHRCl}(\mathrm{R}=\mathrm{H}$ : 76.2, 80.9 $\pm 1,77.9,80.8$ and $78.5 \mathrm{kcal} \mathrm{mol}^{-1} ; \mathrm{R}=\mathrm{Me}: 79.5 \pm 2.1$ and $78.4 \pm 0.4 \mathrm{kcal} \mathrm{mol}^{-1}$ ). For this reason, we have reported in the footnotes of Table 1 several BDE values of compounds that differ by an $\alpha$-Me group from those listed in the Table, when no experimental data on the latter are available. Overall, we feel that the chosen DFT method may give systematic errors in the absolute BDE values, but the relative trends should be quite correctly reproduced. Therefore, a slight decrease of BDE upon addition of an $\alpha$-Me group is likely to be a real effect.

The available experimental BDEs for the chloride and bromide derivatives, with few exceptions, seem to be rather well reproduced by the calculations. A systematic but small error in defect can be noted for the chloride series. On the other hand, the iodides afford calculated values that are in many cases considerably smaller than those provided by the experimental literature. One possible reason for this discrepancy is the large spin-orbit stabilization of atomic iodine (ca. $7 \mathrm{kcal} \mathrm{mol}^{-1}$ ), which must be considered in order to obtain true gas-phase BDE values. The same effect, on the other hand, will play a role in the formation of M-I bonds in transition metal compounds during the activation step of the ATRP process. Therefore, these data will still give meaningful results when combined with computed M-I bond dissociation energies for the purpose of estimating the position of the activation/deactivation equilibria.

The BDE of benzyl derivatives has already been the subject of extensive theoretical work at semi-empirical and DFT levels. ${ }^{35}$ In particular, the recent work of Ingold et al. analyses the effects of para substituents (Y) in $\mathrm{Y}_{-} \mathrm{C}_{6} \mathrm{H}_{4}-\mathrm{CH}_{2}-\mathrm{X}$ on the $\mathrm{C}-\mathrm{X}$ BDE for $\mathrm{X}=\mathrm{Cl}$ 
and $\mathrm{Br}$. The results obtained by these authors at the B3LYP/6-311+G(2d,2p) level for $\mathrm{Y}=\mathrm{H}$ ( 68.6 for $=\mathrm{Cl} ; 57.1$ for $\mathrm{X}=\mathrm{Br}$ ) are slightly lower than those reported by us here, especially when considering that they were apparently not corrected for spin-orbit coupling effects. In summary, the comparison of the calculated BDEs with the relatively small set of available experimental data confirm the suitability of the chosen theoretical method. The values that we have obtained are reasonably accurate in an absolute sense and even more so when taken relative to each other. This computational approach is the best one to start to address fine effects that have been noted experimentally in ATRP.

\section{(e) Comparison with ATRP Equilibrium Constants}

According to Scheme 2, for the same catalytic systems, bond dissociation energies of alkyl halides should directly correlate with atom transfer equilibrium constants. Thus, relative values of free energies of bond dissociation should correspond to the relative values of free energies of the ATRP equilibrium under the same conditions (solvent, temperature, ligands, etc.). Unfortunately there are only a few reliable quantitative measurements of the ATRP equilibrium constants and not all of them were performed under the same conditions.

The rate of ATRP depends on the rate constant of propagation $\left(\mathrm{k}_{\mathrm{p}}\right)$ and on the concentrations of monomer and propagating radical. The latter depends on the ATRP equilibrium constant $\left(\mathrm{K}_{\mathrm{eq}}\right)$ and on the concentrations of dormant species $(\mathrm{R}-\mathrm{X})$, activator (e.g. $\mathrm{Cu}^{\mathrm{I}}$ ) and deactivator (e.g. $\mathrm{X}-\mathrm{Cu}^{\mathrm{II}}$ ), according to Eq. 1 .

$$
R_{p}=k_{p}[M]\left[P^{\bullet}\right]=k_{p} K_{e q}[M][R-X] \frac{\left[C u^{I}\right]}{\left[X-C u^{I I}\right]}
$$


Since in many ATRP systems nearly linear semilogarithmic plots are observed, especially when excess of deactivating $\mathrm{X}-\mathrm{Cu}^{\mathrm{II}}$ species is used, the $\mathrm{K}_{\mathrm{eq}}$ can be calculated according to eq. 2 , in which $-\mathrm{d} \ln [\mathrm{M}] / \mathrm{dt}$ is a slope of the semilogarithmic kinetic plot.

$$
K_{e q}=\frac{(-d \ln [M] / d t)}{k_{p}} \frac{\left[X-C u^{I I}\right]}{[R-X]\left[C u^{I}\right]}
$$

Typically, concentrations of $[\mathrm{R}-\mathrm{X}]$ and $\left[\mathrm{Cu}^{\mathrm{I}}\right]$ are quite close to the initial values (perhaps reduced by less than a few \%). However, the precise measurement of the concentration of the deactivator $\left(\left[\mathrm{X}-\mathrm{Cu}^{\mathrm{II}}\right]\right)$ is more difficult. In many system, its pseudo-equilibrium concentration is established by persistent radical effect ${ }^{36}$ and may very from $1 \%$ to even $>10 \%$ vs. initial $\left[\mathrm{Cu}^{\mathrm{I}}\right]$. However, $\left[\mathrm{X}-\mathrm{Cu}^{\mathrm{II}}\right]$ varies to a much smaller extent, when it is used in a sufficient excess. $^{37}$

In such a way, bulk polymerizations of MMA, MA (or $n \mathrm{BA}$ ) and Sty were studied in the presence of $10 \mathrm{~mol} \%$ of $\mathrm{CuBr}_{2}$ at $90{ }^{\circ} \mathrm{C}$, providing the approximate values of the equilibrium constants illustrated in Table $5 .^{38}$ Detailed ESR studies confirmed that the level of the spontaneously formed $\left[\mathrm{X}-\mathrm{Cu}^{\mathrm{II}}\right]$ was lower than externally added amount. ${ }^{39,40}$ The values reported in Table 5 are similar to earlier reported values for MMA $\left(K_{\mathrm{eq}}=710^{-7}\right)^{41}$, styrene in $50 \% \mathrm{Ph}_{2} \mathrm{O}\left(\mathrm{K}_{\mathrm{eq}}=410^{-8}\right)^{37}$ and MA with $5 \% \mathrm{CuBr}_{2}\left(\mathrm{~K}_{\mathrm{eq}}=210^{-9}\right)^{42}$

\section{Insert Table 5}

Equilibrium constants were also calculated for model systems using the analytical solution of the persistent radical effect. ${ }^{36,43}$ In the absence of monomer, the ATRP equilibrium (Scheme 1) simplifies to three elementary reactions: activation $\left(\mathrm{k}_{\mathrm{a}}\right)$, deactivation 
$\left(\mathrm{k}_{\mathrm{d}}\right)$ and termination $\left(\mathrm{k}_{\mathrm{t}}\right)$. In that case, it was shown that the concentration of generated deactivator $\mathrm{XMt}^{\mathrm{m}+1} / \mathrm{L}_{\mathrm{n}}$ should be proportional to $\mathrm{t}^{1 / 3}$ according to eq. 3 ): $:^{36,43}$

$$
\begin{array}{r}
{\left[X M t^{m+1} / L_{n}\right]=\left(3 K_{e q}{ }^{2} k_{t}[R X]_{0}^{2}\left[M t^{m} / L_{n}\right]_{0}^{2}\right)^{1 / 3} t^{1 / 3}} \\
\frac{\sqrt{8 k_{t}} K_{e q}}{3[R X]_{0} k_{a}^{3 / 2}}<t<\frac{1}{3 K_{e q}^{2} k_{t}[R X]_{0}}
\end{array}
$$

The measurement of $\mathrm{K}_{\mathrm{eq}}$ requires only the knowledge of initial concentrations of $[\mathrm{RX}]_{\mathrm{o}}$ and $\left[\mathrm{Mt}^{\mathrm{m}} / \mathrm{L}_{\mathrm{n}}\right]_{\mathrm{o}}$, and the termination rate constant, $\mathrm{k}_{\mathrm{t}}$, which is often available in the literature. Assumptions can be used for alkyl halides for which $\mathrm{k}_{\mathrm{t}}$ values are not known, since the termination of two small radicals without an unusual steric effect is governed by diffusion limits $\left(2 \mathrm{k}_{\mathrm{t}}=5 \pm 1 \times 10^{9} \mathrm{M}^{-1} \mathrm{~s}^{-1}\right){ }^{44,45}$ The results of such measurements are summarized in Table $6 .^{22}$

\section{Insert Table 6}

In order to compare the experimentally estimated values of ATRP equilibrium constants with those obtained from DFT calculations, we must use their relative values. Table 7 presents relative values of the equilibrium constants of homolytic bond dissociation deduced from DFT calculations at $25{ }^{\circ} \mathrm{C}$ and $90{ }^{\circ} \mathrm{C}$ using methyl 2-halopropionate as the standard $\left(\mathrm{K}_{\mathrm{eq}}\right.$ $=1$ ). The values of $K_{\text {eq }}$ were calculated using $\Delta H^{0}$ and $\Delta S^{0}$ values summarized in Table 1 .

\section{Insert Table 7}

In addition to the experimentally measured values presented in Tables 5 and 6 , some unpublished data or information in literature is available which allows to roughly estimate $\mathrm{K}_{\mathrm{eq}}$ for several other monomers/initiators. 
For instance, our earlier studies of acrylonitrile polymerization initiated by $\mathrm{RCl} / \mathrm{CuCl} / \mathrm{bpy}$, combined with the rough estimate of $\mathrm{AN}$ propagation rate constant, ${ }^{46} \mathrm{k}_{\mathrm{p}}=510^{3}$ $\mathrm{mol}^{-1} \mathrm{~L} \mathrm{~s}^{-1}$ suggest that $\mathrm{K}_{\mathrm{eq}} \sim 10^{-6}$ at $75^{\circ} \mathrm{C}$, a value around 10 times larger than for MMA.

As indicated in Scheme 2, for a given copper(I) complex (all other variables being constant) the difference in the equilibrium constant can be correlated with the $\mathrm{C}-\mathrm{X}$ bond dissociation energy of the corresponding alkyl halide. Generally, one would expect that an increase in $\mathrm{K}_{\mathrm{eq}}$ should be accompanied by a decrease in the equilibrium constant for the homolytic cleavage of the alkyl halide bond. The values of $\mathrm{K}_{\mathrm{eq}}$ for alkyl bromides which are typically used as initiators in the ATRP relative to ma-Br for all copper(I) complexes in $\mathrm{CH}_{3} \mathrm{CN}$ at $298 \mathrm{~K}$ (Table 6) follow the general trend: $m a(1) \approx t b u-m a(1) \approx b z(1)<$ sty $(3)<$ an (1300). The corresponding relative values of $\mathrm{K}_{\mathrm{eq}}$ calculated by DFT (Table 7) are: $b z$ $(0.36)<m a(1)<$ sty $(10)<a n(2500)$. These values are in good agreement, indicating that DFT calculations can be used to predict the trends in the equilibrium constants for alkyl halides which have not yet been determined.

Similarly, the DFT calculated relative values of $\mathrm{K}_{\mathrm{eq}}$ for typical ATRP systems at 363 $\mathrm{K}$ are: MA-Br (1), Sty-Br (6), MMA-Br (30), and AN-Br (700). The values estimated from ATRP experiments (Table 5) at $363 \mathrm{~K}$ are: MA-Br (1), Sty-Br (20), MMA-Br (300), and AN$\mathrm{Br}(\sim 3000)$. These values also correlate surprisingly well with the values estimated by DFT calculations. Some discrepancies in the case of ATRP polymerizations could be due to the fact that some alkyl halides might not be good models for polymeric species. In fact, it has been previously reported that although secondary alkyl halides are good models for the polymeric species, the tertiary alkyl halides are not. This was ascribed to B-strain effect. ${ }^{47}$ This is also reflected in their ability to efficiently initiate polymerization of the related monomers. Thus, 1-phenylethyl halides, alkyl 2-halopropionate and 2-halopropionitrile are good initiators for styrene, acrylates and acrylonitrile, respectively. ${ }^{37,42,48}$ However, alkyl 2- 
bromoisobutyrate is a poor initiator for MMA. ${ }^{47}$ Our recent measurements for the ATRP activation rate constants of monomeric $\mathrm{H}-\mathrm{MMA}-\mathrm{Br}$ and dimer species $\mathrm{H}-\mathrm{MMA}-\mathrm{MMA}-\mathrm{Br}$ indicate that the latter is $\sim 10$ times more reactive. ${ }^{49}$ This value fits better the DFT calculations but also indicates that the DFT calculations presented here should be extended from monomeric to the corresponding dimeric species which better model polymeric chains. Work in this direction is in progress and will be reported separately.

DFT calculations allow to predict $\mathrm{K}_{\mathrm{eq}}$ values for monomers which have or have not yet been polymerized by ATRP. Furthermore, in conjunction with the rates of propagation (eq (1)), they allow the estimation of the hypothetical rates of polymerization $\left(R_{p}\right)$. Shown in Table 8 are rates of propagation and time required to reach $90 \%$ conversion relative to methyl acrylate at $90{ }^{\circ} \mathrm{C}$ as determined from Eq. (1) and Table 7. Thus, under comparable experimental conditions, if ATRP of acrylonitrile would require 1 second to reach 90\% conversion, methyl acrylate will need 2 hours, styrene 22 hours, vinyl acetate 30 years and ethylene 340000 years! Similarly, one can estimate that vinyl chloride should react slower than methyl acrylate, its $\mathrm{K}_{\mathrm{EQ}}$ value is $~ 1,000$ smaller than for MA. Indeed, a successful polymerization of $\mathrm{VCl}$ was reported under heterogeneous conditions. ${ }^{50}$ Vinylidene chloride ( $\mathrm{K}_{\mathrm{EQ}}$ value $\sim 10$ smaller than for MA) was polymerized by ATRP but the resulting polymer was not well controlled, perhaps due to the branching and crosslinking from multiple halogens along the backbone. ${ }^{49}$ Difficulties in butadiene polymerization must originate from potential complexation with the transition metal catalyst rather than from the strong R-X bond. ${ }^{51,52}$ Indeed, allyl halides were used as efficient ATRP initiators. ${ }^{53}$ The compounds with the lowest BDE, namely $\mathrm{CCl}_{4}$ and Tos-Cl, are among the most efficient ATRP initiators according to the calculated very weak bonds to halogen..$^{3,47,54,55}$ 


\section{Conclusions}

We have shown the utility of BDE calculations for the rationalization of different activation efficiencies and polymerization rates. The BDEs obtained by DFT methods are in good quantitative agreement with the available experimental data and reveal fine effects that were previously unappreciated. The $\alpha-\mathrm{H} / \mathrm{CH}_{3}$ substitution introduces a small but systematic weakening of the R-X bond, which is crucial to rationalize, for instance, the very different behavior of MA and MMA. Experimentally determined equilibrium constants for the atom transfer process of different monomers/initiating systems are in good agreement with the relative values of these constants that are derived from DFT computed free energies. Given the relative paucity of experimental BDE data and the difficulty and/or limited precision with which they are obtained, this computational approach offers a valuable tool for predicting the behavior of new monomer/initiating systems.

Supplementary Material. Cartesian coordinates for all optimized compounds.

\section{Acknowledgements}

RP thanks the Conseil Régional de Bourgogne for funding to upgrade the University's computing facilities, CINES for granting free CPU time, and Prof. Vidar R. Jensen for computational advice. KM appreciates support from the National Science Foundation (CHE00-96601). 
Table 1. Calculated ${ }^{\mathrm{a}} \Delta \mathrm{H}^{0}, \Delta \mathrm{S}^{0}$ and $\Delta \mathrm{G}^{0}$ for the $\mathrm{R}-\mathrm{X}$ bond breaking process at $298 \mathrm{~K}$ and comparison with experimental BDE's.

\begin{tabular}{|c|c|c|c|c|c|}
\hline $\mathrm{R}$ & $\mathrm{X}$ & $\begin{array}{c}\Delta \mathrm{H}^{0}{ }_{298} / \\
\mathrm{kcal} \mathrm{mol}^{-1}\end{array}$ & $\begin{array}{c}\Delta \mathrm{S}_{298}^{0} / \\
\text { cal K}^{-1} \mathrm{~mol}^{-1}\end{array}$ & $\begin{array}{c}\Delta \mathrm{G}_{298}^{0} / \\
\mathrm{kcal} \mathrm{mol}^{-1}\end{array}$ & $\begin{array}{c}\text { Experimental }{ }^{\mathrm{b}} \text { BDE's/ } \\
\mathrm{kcal} \mathrm{mol}^{-1}\end{array}$ \\
\hline & $\mathrm{Cl}$ & 83.1 & 33.4 & 73.1 & $84.2 \pm 0.8$ \\
\hline & $\mathrm{Cl}^{\mathrm{c}}$ & 82.9 & 32.5 & 73.2 & \\
\hline \multirow[t]{4}{*}{ et } & $\mathrm{Br}$ & 73.1 & 33.0 & 63.2 & $70.0 \pm 1.0$ \\
\hline & $\mathrm{I}$ & 53.0 & 32.5 & 43.3 & $55.8 \pm 1.5$ \\
\hline & $\mathrm{N}_{3}$ & 70.7 & 38.4 & 59.2 & \\
\hline & $\mathrm{S}_{2} \mathrm{CNMe}_{2}$ & 56.6 & 39.3 & 44.8 & \\
\hline \multirow[t]{2}{*}{$v d f$} & $\mathrm{Cl}$ & 82.8 & 33.5 & 72.8 & \\
\hline & $\mathrm{Br}$ & 71.8 & 33.0 & 61.9 & $68.6 \pm 1.3$ \\
\hline \multirow[t]{2}{*}{$v f$} & $\mathrm{Cl}$ & 82.5 & 33.0 & 72.6 & $84.7 \pm 2.8$ \\
\hline & $\mathrm{Br}$ & 71.8 & 32.6 & 62.1 & \\
\hline \multirow[t]{4}{*}{ ve } & $\mathrm{Cl}$ & 82.2 & 34.1 & 72.1 & \\
\hline & $\mathrm{Br}$ & 73.3 & 33.8 & 63.2 & \\
\hline & $\mathrm{Cl}$ & 81.8 & 35.9 & 71.2 & $84.6 \pm 1.5$ \\
\hline & $\mathrm{Br}$ & 72.3 & 35.5 & 61.7 & $65.5,71.5 \pm 1.5$ \\
\hline \multirow[t]{5}{*}{$i p r$} & I & 50.2 & 34.9 & 39.8 & $56.1 \pm 1.5,53.4$ \\
\hline & $\mathrm{N}_{3}$ & 69.6 & 41.5 & 57.2 & \\
\hline & $\mathrm{S}_{2} \mathrm{CNMe}_{2}$ & 53.2 & 46.0 & 39.5 & \\
\hline & $\mathrm{Cl}$ & 80.1 & 37.5 & 69.0 & $84.1 \pm 1.5$ \\
\hline & $\mathrm{Br}$ & 71.2 & 37.1 & 60.1 & $70.0 \pm 1.5$ \\
\hline \multirow[t]{4}{*}{$t b u$} & $\mathrm{I}$ & 47.3 & 36.7 & 36.4 & $54.3 \pm 1.5,52.1$ \\
\hline & $\mathrm{N}_{3}$ & 67.8 & 43.6 & 54.8 & \\
\hline & $\mathrm{S}_{2} \mathrm{CNMe}_{2}$ & 46.7 & 44.8 & 33.3 & \\
\hline & $\mathrm{Cl}$ & 79.5 & 33.7 & 69.4 & \\
\hline \multirow{2}{*}{ voac } & $\mathrm{Br}$ & 69.5 & 33.4 & 59.5 & \\
\hline & $\mathrm{I}$ & 45.2 & 33.1 & 35.3 & \\
\hline \multirow[t]{2}{*}{$v b r$} & $\mathrm{Cl}$ & 77.2 & 33.8 & 67.1 & $79.3 \pm 2.0$ \\
\hline & $\mathrm{Br}$ & 67.5 & 33.5 & 57.5 & \\
\hline \multirow[t]{2}{*}{$v c l$} & $\mathrm{Cl}$ & 76.0 & 34.1 & 65.9 & $79.5 \pm 2.1,78.4 \pm 0.4$ \\
\hline & $\mathrm{Br}$ & 66.0 & 33.7 & 55.9 & $65 \pm 2$ \\
\hline \multirow[t]{2}{*}{ dmam } & $\mathrm{Cl}$ & 72.5 & 34.6 & 62.2 & \\
\hline & $\mathrm{Br}$ & 64.8 & 35.8 & 54.2 & \\
\hline \multirow[t]{2}{*}{$v k$} & $\mathrm{Cl}$ & 71.0 & 32.5 & 61.3 & \\
\hline & $\mathrm{Br}$ & 62.9 & 32.1 & 53.3 & $\mathrm{~d}$ \\
\hline \multirow[t]{4}{*}{ dcm } & $\mathrm{Cl}$ & 70.2 & 34.6 & 59.9 & $76.2,80.9 \pm 1,73.6$ \\
\hline & $\mathrm{Br}$ & 60.0 & 32.0 & 50.5 & \\
\hline & $\mathrm{Cl}$ & 69.9 & 31.7 & 60.4 & $\mathrm{e}$ \\
\hline & $\mathrm{Br}$ & 61.4 & 31.9 & 51.8 & \\
\hline \multirow[t]{4}{*}{$m a$} & $\mathrm{I}$ & 38.4 & 31.4 & 29.0 & \\
\hline & $\mathrm{N}_{3}$ & 59.0 & 38.8 & 47.5 & \\
\hline & $\mathrm{S}_{2} \mathrm{CNMe}_{2}$ & 43.6 & 37.8 & 32.4 & \\
\hline & $\mathrm{Cl}$ & 69.4 & 28.7 & 60.8 & $72.9 \pm 2,71.6$ \\
\hline$b z$ & $\mathrm{Br}$ & 60.2 & 26.8 & 52.5 & $60.0 \pm 3,55.9,60.7 \pm 1,55.1 \pm 2.5,56.1 \pm 2$ \\
\hline
\end{tabular}




\begin{tabular}{lccccl}
\hline & $\mathrm{I}$ & 38.7 & 28.3 & 30.2 & $45.4,43.9 \pm 2,43.5 \pm 2$ \\
\hline & $\mathrm{Cl}$ & 68.5 & 32.6 & 58.8 & \\
\multirow{4}{*}{ sty } & $\mathrm{Br}$ & 59.9 & 32.2 & 50.3 & \\
& $\mathrm{I}$ & 35.8 & 31.7 & 26.4 & \\
& $\mathrm{~N}_{3}$ & 57.0 & 38.5 & 45.5 & \\
& $\mathrm{~S}_{2} \mathrm{CNMe}_{2}$ & 40.9 & 38.2 & 29.5 & \\
\multirow{4}{*}{$m a$} & $\mathrm{Cl}$ & 66.9 & 31.9 & 57.4 & \\
& $\mathrm{Br}$ & 58.9 & 31.6 & 49.4 & \\
\hline an & $\mathrm{I}$ & 33.7 & 31.2 & 24.4 & \\
& $\mathrm{Cl}$ & 65.9 & 33.8 & 55.8 & $\mathrm{f}$ \\
\hline all & $\mathrm{Br}$ & 57.2 & 33.5 & 47.2 & \\
& $\mathrm{Cl}$ & 65.4 & 31.9 & 55.8 & $\mathrm{~g}$ \\
\hline tcm & $\mathrm{Br}$ & 56.4 & 31.6 & 46.9 & $\mathrm{~h}$ \\
& $\mathrm{Cl}$ & 62.7 & 35.5 & 52.1 & $70.4 \pm 1,70.8 \pm 1.3,70,70.9$ \\
& $\mathrm{Br}$ & 53.1 & 32.9 & 43.3 & $55.3 \pm 1$ \\
\hline tos & $\mathrm{Cl}$ & 55.2 & 32.1 & 45.7 & \\
& $\mathrm{Br}$ & 48.9 & 31.0 & 39.6 & \\
\hline
\end{tabular}

${ }^{a}$ All calculations carried out with the $6-31 G^{* *}$ basis set unless otherwise stated. ${ }^{b}$ Values obtained from ref. ${ }^{23}$. ${ }^{\mathrm{c}}$ Calculations carried out with an augmented basis set (see Experimental). ${ }^{\mathrm{d}}$ For the related 1-bromoacetone is reported $\mathrm{BDE}=62.5 \mathrm{kcal} \mathrm{mol}^{-1}$. ${ }^{\mathrm{e}}$ For the related methyl-2-chloroacetate is reported $\mathrm{BDE}=72.1 \mathrm{kcal} \mathrm{mol}^{-1}$. ${ }^{\mathrm{f}}$ For the related 2chloroethanenitrile is reported $\mathrm{BDE}=63.9 \mathrm{kcal} \mathrm{mol}^{-1}$. ${ }^{\mathrm{g}}$ For the related 3-chloro-1-propene is reported $\mathrm{BDE}=71.3 \pm 1.2 \mathrm{kcal} \mathrm{mol}^{-1}$. h For the related 3-bromo-1-propene is reported BDE $=$ $56.7 \pm 1.2 \mathrm{kcal} \mathrm{mol}^{-1}$. 
Table 2. Relative energies ( $\mathrm{kcal} \mathrm{mol}^{-1}$ ) for different conformations of the $\mathrm{C}-\mathrm{C}(\mathrm{O})-\mathrm{O}-\mathrm{C}$ moiety (bold bonds) for the ma, mma and voac systems.

$m a$<smiles>CCC(=O)OC</smiles><smiles>CC=CC(=O)OC</smiles>

4.8

1.5

7.8

0

0 $m m a$<smiles>COC(=O)C(C)C</smiles><smiles>CC(C)C(=O)OO</smiles><smiles>CCOC(C)=O</smiles><smiles>CCOC(C)=O</smiles>

$\mathrm{MM+}$

PM3
0

0

0
5.6

0.5

12.1 voac

DFT

-

7


Table 3. DFT-calculated degree of pyramidalization (sum of the three bond angles in ${ }^{\circ}$ ) at the carbon atom ${ }^{\mathrm{a}}$ bearing the unpaired electron for the radical species.

$\begin{array}{cccccccccc}e t & v d f & v f & v e & i p r & t b u & v o a c & v b r & v c l & d m a m \\ 359.3 & 350.4 & 352.1 & 351.6 & 358.4 & 356.6 & 360.0 & 356.4 & 357.4 & 359.9 \\ v k & d c m & m a & b z & s t y & m m a & a n & \text { all } & t c m & t o s \\ 360.0 & 354.1 & 360.0 & 360.0 & 360.0 & 360.0 & 360.0 & 360.0 & 351.6 & 337.1\end{array}$

${ }^{a}$ Except for tos, where the unpaired electron is located on a sulfur atom. 
Table 4. X-C-A-B torsion angles $\left(^{\circ}\right)$ and relative energies $\left(\mathrm{kcal} \mathrm{mol}^{-1}\right)$ of optimized $\mathrm{MM}+$, $\mathrm{PM} 3$ and DFT structures for $\mathrm{R}-\mathrm{X}(\mathrm{R}=m a, m m a, v k$ and voac; $\mathrm{X}=\mathrm{Cl}, \mathrm{Br})$ compounds. ${ }^{\mathrm{a}}$

\begin{tabular}{|c|c|c|c|c|c|c|}
\hline & \multicolumn{2}{|c|}{ MM+ } & \multicolumn{2}{|c|}{ PM3 } & \multicolumn{2}{|c|}{ DFT } \\
\hline & $\theta$ & $\mathrm{E}$ & $\theta$ & $\mathrm{E}$ & $\theta$ & $\mathrm{E}$ \\
\hline \multirow{3}{*}{ ma-cl } & 118.8 & 0 & 132.2 & 0 & 81.2 & 0 \\
\hline & 4.8 & 3.7 & -46.6 & 0.1 & -68.6 & 0.5 \\
\hline & 169.3 & 5.5 & & & & \\
\hline \multirow{3}{*}{ ma-br } & 60.4 & 0 & 95.8 & 1.1 & 58.7 & 0 \\
\hline & -55.8 & 0.5 & -22.4 & 0 & -71.2 & 0.7 \\
\hline & & & 17.5 & 0.1 & & \\
\hline \multirow{4}{*}{ ma-i } & 121.7 & 0.2 & 106.4 & 0.6 & 80.0 & 0 \\
\hline & -57.0 & 0 & -30.7 & 0 & -82.2 & 0.8 \\
\hline & 29.6 & 1.1 & 32.7 & 0.2 & & \\
\hline & & & 124.3 & 0.1 & & \\
\hline \multirow{3}{*}{ mma-cl } & 52.5 & 0 & 31.6 & 0 & 72.6 & 0 \\
\hline & 0.3 & 3.2 & 0.3 & 0.1 & 0.4 & 1.2 \\
\hline & 179.9 & 5.5 & 178.3 & 0.3 & & \\
\hline \multirow{3}{*}{ mma-br } & 51.7 & 0 & $\mathrm{~b}$ & & 73.8 & 0 \\
\hline & -55.8 & 0.4 & 0.6 & 0 & 9.7 & 1.9 \\
\hline & & & 179.2 & 1.5 & & \\
\hline \multirow{3}{*}{ mma-i } & 66.1 & 0 & 26.4 & 0 & 74.9 & 0 \\
\hline & & & 2.0 & 0.1 & 0.1 & 2.7 \\
\hline & 178.7 & 2.4 & 179.4 & 0.3 & & \\
\hline \multirow{3}{*}{ vk-cl } & 36.2 & 0 & 65.6 & 0.6 & 46.0 & 0 \\
\hline & $\mathrm{c}$ & & -44.6 & 0 & -24.6 & 0.4 \\
\hline & 172.2 & 2.4 & & & & \\
\hline \multirow{4}{*}{ vk-br } & 63.7 & 0 & 69.7 & 0.7 & 69.3 & 0 \\
\hline & -76.4 & 1.5 & -32.4 & 0 & -41.4 & 1.1 \\
\hline & -48.0 & 1.6 & -55.4 & 0.2 & & \\
\hline & & & 35.8 & 0.5 & & \\
\hline \multirow{5}{*}{ voac-cl ${ }^{\mathrm{d}}$} & e & & 86.1 & 0.4 & 90.6 & 0 \\
\hline & 159.9 & 0 & & & $f$ & f \\
\hline & -78.5 & 1.8 & & & & \\
\hline & (89.1) & $(4.2)$ & $(84.6)$ & (1.0) & $(80.2)$ & $(7.3)$ \\
\hline & & & $(-62.4)$ & $(0)$ & $(-69.8)$ & (11.6) \\
\hline \multirow{6}{*}{ voac-br ${ }^{\mathrm{d}}$} & 83.8 & 0 & 100.2 & 0.1 & 84.4 & 0 \\
\hline & 158.9 & 0.4 & & & & \\
\hline & 106.6 & 1.2 & & & & \\
\hline & -80.3 & 2.1 & & & & \\
\hline & $(92.9)$ & (4.6) & $(79.8)$ & $(0.3)$ & $(77.8)$ & $(5.9)$ \\
\hline & (145.9) & $(4.5)$ & $(-60.7)$ & $(0)$ & $(-70.9)$ & (10.0) \\
\hline \multirow{5}{*}{ voac- $i^{\mathrm{d}}$} & 94.2 & 0.6 & 119.0 & 0 & 88.1 & 0 \\
\hline & 157.8 & 0 & & & $\mathrm{~g}$ & $\mathrm{~g}$ \\
\hline & -78.6 & 1.4 & & & & \\
\hline & (145.0) & (3.8) & (166.4) & (1.8) & & \\
\hline & $(95.0)$ & $(4.0)$ & (106.5) & $(0.7)$ & & \\
\hline
\end{tabular}




$\begin{array}{ccccccc} & 65.1 & 0 & 136.8 & 0 & 74.9 & 0 \\ \text { dmam-cl } & 150.7 & 1.0 & -36.9 & 0.4 & & \\ & -66.9 & 2.2 & 175.2 & 0.7 & & \\ \text { dmam-br } & 79.5 & 0 & 101.3 & 0 & 76.6 & 0 \\ & 124.6 & 1.8 & 91.7 & 0.1 & & \end{array}$

${ }^{\text {a}}$ For systems having a chiral $\mathrm{C}$ atom ( $m a, v k$, voac and $\mathrm{dmam}$ ), the diheadral angles refer to the molecules with the same $(S)$ absolute configuration. ${ }^{\text {bPM} 3}$ optimization starting from the best DFT geometry led again to the best PM3 geometry $\left(\theta=0.6^{\circ}\right)^{\mathrm{C}} \mathrm{MM}+$ optimization starting from the second best DFT geometry $\left(\theta=-24.6^{\circ}\right)$ led again to the best MM+ geometry $\left(\theta=36.2^{\circ}\right){ }^{d}$ Values in parentheses refer to the conformation having a $\mathrm{C}-\mathrm{O}-\mathrm{C}(\mathrm{O})-\mathrm{C}$ dihedral angle close to $0^{\circ}$. ${ }^{\mathrm{e}} \mathrm{MM}+$ optimization starting from the best DFT geometry $\left(\theta=90.6^{\circ}\right)$ led again to the best $\mathrm{MM}+$ geometry $\left(\theta=159.9^{\circ}\right) .{ }^{\mathrm{f}} \mathrm{DFT}$ optimization starting from the best MM+ geometry $\left(\theta=159.9^{\circ}\right)$ led again to the best DFT geometry $\left(\theta=90.6^{\circ}\right)$. $^{\text {gDFT }}$ optimization starting from the best MM+ geometry $\left(\theta=157.8^{\circ}\right)$ led again to the best DFT geometry $(\theta=$ $\left.88.1^{\circ}\right)$. 
Table 5. ATRP equilibrium constants for three representative monomers at $90 \mathrm{C}^{38}$.

\begin{tabular}{|l|l|l|l|}
\hline Monomer & $k_{p}{ }^{a p p}, \mathrm{~s}^{-1}$ & $k_{p}, \mathrm{M}^{-1} \mathrm{~s}^{-1}$ & $K_{e q}$ \\
\hline mma & $2 \times 10^{-4}$ & 1615 & $7 \times 10^{-7}$ \\
\hline sty & $2 \times 10^{-6}$ & 895 & $4 \times 10^{-8}$ \\
\hline$b a$ & $5 \times 10^{-7}$ & 56780 & $4 \times 10^{-10}$ \\
\hline
\end{tabular}

$K_{e q}$ values obtained from ATRP using $\mathrm{Cu}(\mathrm{I}) \mathrm{Br} / \mathrm{Cu}(\mathrm{II}) \mathrm{Br}_{2} / \mathrm{dNbpy}$ catalyst system at $90^{\circ} \mathrm{C},[\mathrm{M}]_{\mathrm{o}}:\left[\mathrm{Cu}^{\mathrm{I}}\right]_{\mathrm{o}}:\left[\mathrm{Cu}^{\mathrm{II}}\right]_{\mathrm{o}}:[\text { ethyl 2-bromoisobutyrate }]_{\mathrm{o}}=500: 1: 0.1: 1$

Rate constants of propagation $\left(k_{p}\right) \quad$ Ref. ${ }^{56}$ 
Table 6. Equilibrium constants $\left(K_{e q}\right)$ for various alkyl bromides and copper(I) complexes used in the ATRP at $25^{\circ} \mathrm{C}$ in $\mathrm{CH}_{3} \mathrm{CN}$.

\begin{tabular}{|c|c|c|}
\hline $\mathrm{Cu}^{\mathrm{I}}$ Complex & $R-\mathrm{Br}$ & $K_{e q}$ \\
\hline \multirow[t]{5}{*}{$\mathrm{Cu}^{\mathrm{I}} \mathrm{Br} / 2 \mathrm{bpy}$} & $b z$ & $1.4 \times 10^{-10}$ \\
\hline & sty & $6.1 \times 10^{-10}$ \\
\hline & $m a$ & $1.2 \times 10^{-10}$ \\
\hline & $t b u-a$ & $1.1 \times 10^{-10}$ \\
\hline & an & $1.6 \times 10^{-7}$ \\
\hline \multirow[t]{3}{*}{$\mathrm{Cu}^{\mathrm{I}} \mathrm{Br} / \mathrm{PMDETA}$} & $b z$ & $8.0 \times 10^{-9}$ \\
\hline & sty & $2.2 \times 10^{-8}$ \\
\hline & $m a$ & $1.1 \times 10^{-8}$ \\
\hline \multirow[t]{2}{*}{ Cu'Br/HMTETA } & sty & $5.0 \times 10^{-8}$ \\
\hline & $m a$ & $4.7 \times 10^{-8}$ \\
\hline \multirow[t]{3}{*}{$\mathrm{Cu}^{\mathrm{I} B r} / \mathrm{Me}_{6} \mathrm{TREN}$} & $b z$ & $3.1 \times 10^{-7}$ \\
\hline & sty & $8.0 \times 10^{-7}$ \\
\hline & $m a$ & $4.2 \times 10^{-7}$ \\
\hline
\end{tabular}


Table 7. Values of $K_{e q}$ for homolytic bond cleavage of alkyl halides deduced from DFT calculations at $25{ }^{\circ} \mathrm{C}$ and $90{ }^{\circ} \mathrm{C}$ relative to methyl 2-halopropionate $\left(K_{e q}=1\right)$.

\begin{tabular}{|c|c|c|c|c|c|c|}
\hline \multirow[t]{2}{*}{$\mathbf{R}$} & \multicolumn{2}{|c|}{ RCl } & \multicolumn{2}{|c|}{$\mathbf{R B r}$} & \multicolumn{2}{|c|}{ RI } \\
\hline & $K_{e q}(298)$ & $K_{e q}(363)$ & $K_{e q}(298)$ & $K_{e q}(363)$ & $K_{e q}(298)$ & $K_{e q}(363)$ \\
\hline et & $4.35 \times 10^{-10}$ & $2.22 \times 10^{-8}$ & $4.55 \times 10^{-9}$ & $1.56 \times 10^{-7}$ & $3.34 \times 10^{-11}$ & $2.77 \times 10^{-9}$ \\
\hline$v d f$ & $7.85 \times 10^{-10}$ & $3.93 \times 10^{-8}$ & $4.01 \times 10^{-8}$ & $9.40 \times 10^{-7}$ & & \\
\hline$v f$ & $1.14 \times 10^{-9}$ & $5.12 \times 10^{-8}$ & $2.86 \times 10^{-8}$ & $6.80 \times 10^{-7}$ & & \\
\hline ve & $2.88 \times 10^{-9}$ & $1.20 \times 10^{-7}$ & $4.78 \times 10^{-9}$ & $1.76 \times 10^{-7}$ & & \\
\hline$i p r$ & $1.36 \times 10^{-8}$ & $5.05 \times 10^{-7}$ & $5.91 \times 10^{-8}$ & $1.61 \times 10^{-6}$ & $1.13 \times 10^{-8}$ & $4.10 \times 10^{-7}$ \\
\hline$t b u$ & $5.68 \times 10^{-7}$ & $1.25 \times 10^{-5}$ & $8.96 \times 10^{-7}$ & $1.73 \times 10^{-5}$ & $3.82 \times 10^{-6}$ & $5.84 \times 10^{-5}$ \\
\hline voac & $2.57 \times 10^{-7}$ & $4.64 \times 10^{-6}$ & $2.34 \times 10^{-6}$ & $2.75 \times 10^{-5}$ & $2.33 \times 10^{-5}$ & $1.84 \times 10^{-4}$ \\
\hline$v b r$ & $1.38 \times 10^{-5}$ & $1.24 \times 10^{-4}$ & $7.59 \times 10^{-5}$ & $4.80 \times 10^{-4}$ & & \\
\hline$v c l$ & $1.01 \times 10^{-4}$ & $6.54 \times 10^{-4}$ & $1.02 \times 10^{-3}$ & $4.12 \times 10^{-3}$ & & \\
\hline dmam & $5.48 \times 10^{-2}$ & $1.19 \times 10^{-1}$ & $2.03 \times 10^{-2}$ & $5.80 \times 10^{-2}$ & & \\
\hline$v k$ & $2.15 \times 10^{-1}$ & $3.04 \times 10^{-1}$ & $8.09 \times 10^{-2}$ & $1.29 \times 10^{-1}$ & & \\
\hline$b z$ & $5.01 \times 10^{-1}$ & $4.29 \times 10^{-1}$ & $3.12 \times 10^{-1}$ & $3.69 \times 10^{-1}$ & $1.21 \times 10^{-1}$ & $1.36 \times 10^{-1}$ \\
\hline$m a$ & 1 & 1 & 1 & 1 & 1 & 1 \\
\hline$d c m$ & 2.45 & 2.73 & 9.76 & 6.69 & & \\
\hline sty & $1.62 \times 10^{1}$ & $1.06 \times 10^{1}$ & $1.42 \times 10^{1}$ & 5.56 & $8.33 \times 10^{1}$ & $3.93 \times 10^{1}$ \\
\hline$m m a$ & $1.61 \times 10^{2}$ & $6.62 \times 10^{1}$ & $5.84 \times 10^{1}$ & $2.78 \times 10^{1}$ & $2.24 \times 10^{3}$ & $5.56 \times 10^{2}$ \\
\hline an & $2.40 \times 10^{3}$ & $7.23 \times 10^{2}$ & $2.52 \times 10^{3}$ & $7.29 \times 10^{2}$ & & \\
\hline all & $2.32 \times 10^{3}$ & $5.90 \times 10^{2}$ & $3.98 \times 10^{3}$ & $8.90 \times 10^{2}$ & & \\
\hline tcm & $1.19 \times 10^{6}$ & $1.41 \times 10^{5}$ & $1.88 \times 10^{6}$ & $1.59 \times 10^{5}$ & & \\
\hline tos & $6.50 \times 10^{10}$ & $7.94 \times 10^{8}$ & $9.24 \times 10^{8}$ & $2.16 \times 10^{7}$ & & \\
\hline
\end{tabular}


Table 8. Rates of propagation and time required to reach $90 \%$ conversion relative to methyl acrylate at $90{ }^{\circ} \mathrm{C}$ as determined from Eq. (1) and Table 7.

\begin{tabular}{|c|c|c|c|c|}
\hline Monomer & $k_{p} / \mathrm{M}^{-1} \mathrm{~s}^{-1}$ & $K_{e q}{ }^{R E L}$ & $R_{p}^{R E L}$ & $t^{R E L}$ \\
\hline an & $5400^{\mathrm{a}}$ & $7.29 \times 10^{2}$ & $7.0 \times 10^{3 \mathrm{a}}$ & $1.4 \times 10^{-4}$ \\
sty & $52150^{\mathrm{b}}$ & 1 & 1 & 1 \\
voac & $850^{\mathrm{b}}$ & 5.56 & $0.090^{\mathrm{b}}$ & 11 \\
et & $14200^{\mathrm{b}}$ & $2.75 \times 10^{-5}$ & $7.5 \times 10^{-6 \mathrm{~b}}$ & $1.3 \times 10^{5}$ \\
& $220^{\mathrm{b}}$ & $1.56 \times 10^{-7}$ & $6.6 \times 10^{-10 \mathrm{~b}}$ & $1.5 \times 10^{9}$ \\
\hline
\end{tabular}

${ }^{\mathrm{a}}$ Ref 46. ${ }^{\mathrm{b}}$ Ref 56. ${ }^{\mathrm{c}}$ Values for RBr, Table 7. 
Scheme 1. Reactions involved in ATRP.

$$
\begin{aligned}
& \mathrm{Mt}^{\mathrm{m}} / \mathrm{L}_{\mathrm{n}}+\mathrm{R}-\mathrm{X} \frac{\mathrm{k}_{\text {act }}}{\mathrm{k}_{\text {deact }}} \mathrm{X}-\mathrm{Mt}^{\mathrm{m}+1} / \mathrm{L}_{\mathrm{n}}+\mathrm{L}_{\mathrm{n}=\text { complexing ligand }}^{\mathrm{X}=\mathrm{Br} \text { or } \mathrm{Cl}} \\
& \mathrm{R}-\mathrm{R} / \mathrm{R}^{\mathrm{H}} \& \mathrm{R}^{=}
\end{aligned}
$$

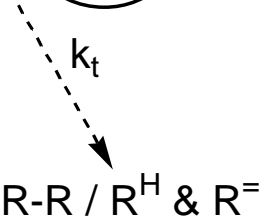

Scheme 2. Reactions contributing to atom transfer equilibrium: redox processes, homolytic bond dissociation of alkyl halide and heterolytic cleavage of $\mathrm{Mt}^{\mathrm{m}+1}-\mathrm{X}$ bond.

\section{Atom Transfer (Overall Equilibrium)}

$$
\mathrm{R}-\mathrm{X}+\mathrm{Mt}^{\mathrm{m}} / \mathrm{L}_{\mathrm{n}}-\frac{\mathrm{k}_{\text {act }}}{\mathrm{k}_{\text {deact }}} \mathrm{R}^{\cdot}+\mathrm{X}-\mathrm{Mt}^{\mathrm{m}+1} / \mathrm{L}_{\mathrm{n}}
$$

\section{Contributing Reactions}

$$
\begin{aligned}
& \mathrm{Mt}^{\mathrm{m}} / \mathrm{L}_{\mathrm{n}} \stackrel{\mathrm{K}_{\mathrm{ET}}}{\rightleftharpoons} \mathrm{Mt}^{\mathrm{m}+1} / \mathrm{L}_{\mathrm{n}}+\mathrm{e}^{\Theta} \\
& x^{\cdot}+e^{\ominus} \stackrel{\mathrm{K}_{\mathrm{EA}}}{=} x^{\ominus} \\
& \mathrm{R}-\mathrm{X} \stackrel{\mathrm{K}_{\mathrm{BD}}}{=} \mathrm{R}^{\cdot}+\mathrm{X}^{\cdot} \\
& \mathrm{X}^{\Theta}+\mathrm{Mt}^{\mathrm{m}+1} / \mathrm{L}_{\mathrm{n}} \stackrel{\mathrm{K}_{\mathrm{HP}}}{=} \mathrm{X}-\mathrm{Mt}^{\mathrm{m}+1} / \mathrm{L}_{\mathrm{n}} \\
& \mathrm{K}_{\mathrm{ATRP}}=\frac{\mathrm{K}_{\mathrm{act}}}{\mathrm{k}_{\text {deact }}}=\mathrm{K}_{\mathrm{EA}} \mathrm{K}_{\mathrm{BD}} \mathrm{K}_{\mathrm{HP}} \mathrm{K}_{\mathrm{ET}} \text { or } \frac{\mathrm{K}_{\mathrm{ATRP}}}{\mathrm{K}_{\mathrm{HP}} \mathrm{K}_{\mathrm{EA}} \mathrm{K}_{\mathrm{ET}}}=\mathrm{K}_{\mathrm{BD}}
\end{aligned}
$$


Scheme 3. R-X compounds and their abbreviations.
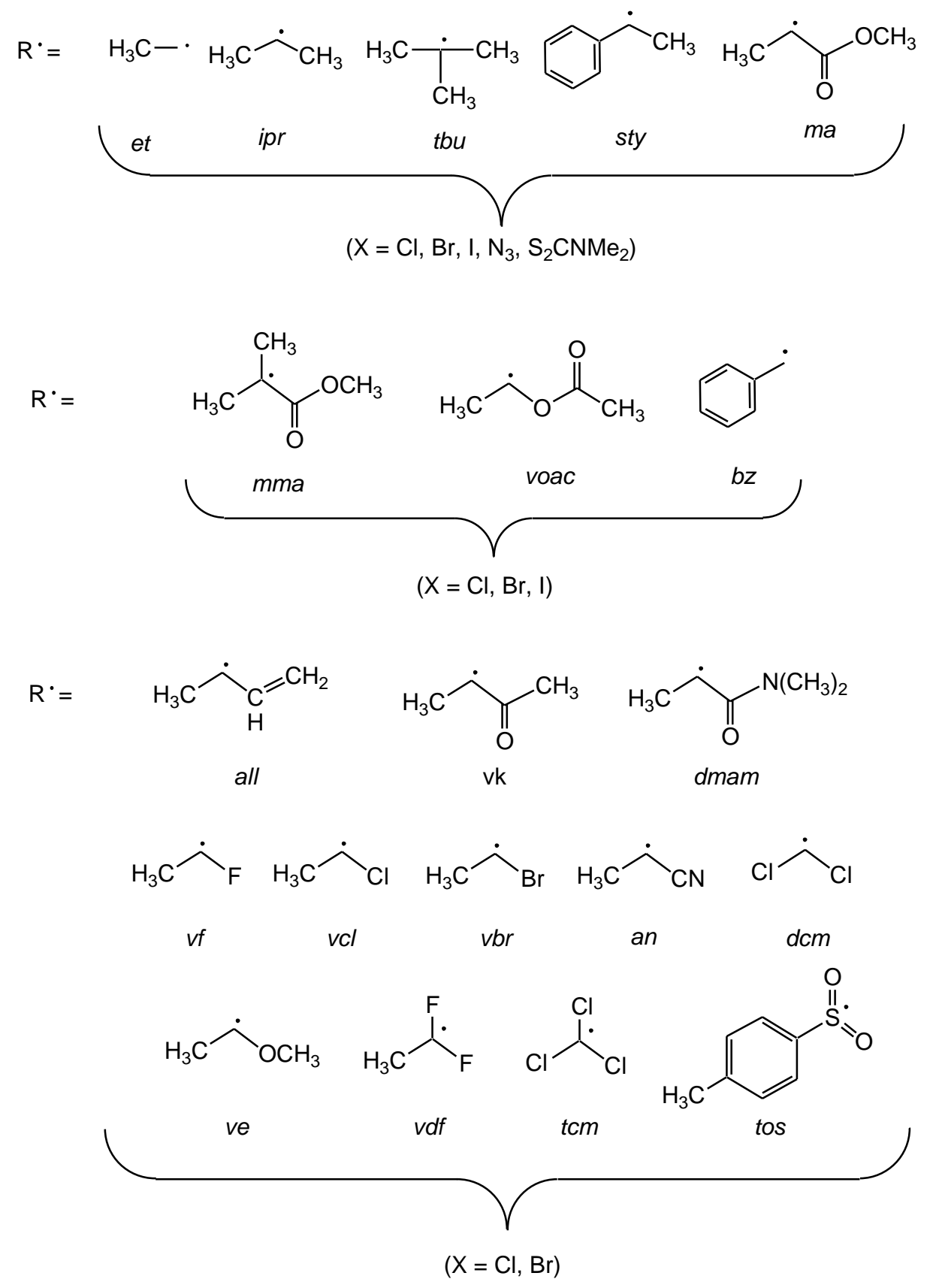
Scheme 4. Definition of the $\mathrm{X}-\mathrm{C}-\mathrm{A}-\mathrm{B}$ dihedral angle $(\mathrm{X}=\mathrm{Cl}, \mathrm{Br})$.

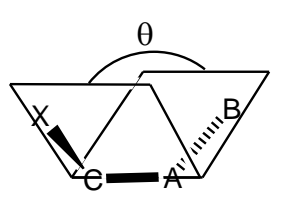

\begin{tabular}{l|c|l} 
& $\mathrm{A}$ & $\mathrm{B}$ \\
\hline $\mathrm{ma}$ & $\mathrm{CO}$ & $\mathrm{OCH}_{3}$ \\
$\mathrm{mma}$ & $\mathrm{CO}$ & $\mathrm{OCH}_{3}$ \\
$\mathrm{vk}$ & $\mathrm{CO}$ & $\mathrm{CH}_{3}$ \\
dmam & $\mathrm{CO}$ & $\mathrm{N}^{\left(\mathrm{CH}_{3}\right)_{2}}$ \\
voac & $\mathrm{O}$ & $\mathrm{COCH}_{3}$
\end{tabular}




\section{References}

(1) Wang, J. S.; Matyjaszewski, K. J. Am. Chem. Soc. 1995, 117, 5614.

(2) Matyjaszewski, K.; Xia, J. Chem. Rev. 2001, 101, 2921.

(3) Kamigaito, M.; Ando, T.; Sawamoto, M. Chem. Rev. 2001, 101, 3689.

(4) Matyjaszewski, K., Ed. Controlled Radical Polymerization; American Chemical Society: Washington, DC, 1998; Vol. 685.

(5) Matyjaszewski, K., Ed. Controlled/Living Radical Polymerization: Progress in ATRP, NMP, and RAFT; American Chemical Society: Washington, DC, 2000; Vol. 768.

(6) Matyjaszewski, K., Ed. Advances in Controlled/Living Radical Polymerization; American Chemical Society: Washington, DC, 2003; Vol. 854.

(7) Matyjaszewski, K.; Davis, T. P. Handbook of Radical Polymerization; WileyInterscience: Hoboken, 2002.

(8) Patten, T. E.; Matyjaszewski, K. Adv. Mater. 1998, 10, 901.

(9) Patten, T. E.; Matyjaszewski, K. Acc. Chem. Res. 1999, 32, 895.

(10) Matyjaszewski, K. Chem. Eur. J. 1999, 5, 3095.

(11) Coessens, V.; Pintauer, T.; Matyjaszewski, K. Prog. Polym. Sci. 2001, 26, 337.

(12) Davis, K. A.; Matyjaszewski, K. Adv. Polym. Sci. 2002, 159, 2.

(13) Pyun, J.; Matyjaszewski, K. Chem. Mater. 2001, 13, 3436.

(14) Patten, T. E.; Xia, J.; Abernathy, T.; Matyjaszewski, K. Science 1996, 272, 866.

(15) Matyjaszewski, K. J. Macromol. Sci., Pure Appl. Chem. 1997, A34, 1785.

(16) Matyjaszewski, K. Macromolecules 1998, 31, 4710.

(17) Matyjaszewski, K. Macromol. Symp. 1998, 134, 105.

(18) Matyjaszewski, K. ACS Symp. Ser. 1998, 685, 258.

(19) Grognec, E. L.; Claverie, J.; Poli, R. J. Am. Chem. Soc. 2001, 123, 9513.

(20) Qiu, J.; Matyjaszewski, K.; Thouin, L.; Amatore, C. Macromol. Chem. Phys. 2000, $201,1625$.

(21) Matyjaszewski, K.; Goebelt, B.; Paik, H.-j.; Horwitz, C. P. Macromolecules 2001, 34, 430.

(22) Pintauer, T.; McKenzie, B.; Matyjaszewski, K. ACS Symp. Ser. 2003, 854, 130.

(23) Luo, Y.-R. Handbook of Bond Dissociation Enrgies in Organic Compounds; CRC Press: Boca Raton, 2003.

(24) Norrby, P.; Liljefors, T. J. Comput. Chem. 1998, 19, 1146.

(25) Mohamadi, F.; Richards, N.; Guida, W.; Liskamp, R.; Lipton, M.; Caufield, C.; Chang, G.; Hendrickson, T.; Still, W. J. Comput. Chem. 1990, 11, 440.

(26) Perdew, J. P. Physical Review B-Condensed Matter 1986, 33, 8822.

(27) Check, C. E.; Faust, T. O.; Bailey, J. M.; Wright, B. J.; Gilbert, T. M.; Sunderlin, L. S. J. Phys. Chem. A 2001, 105, 8111.

(28) Wadt, W. R.; Hay, P. J. J. Chem. Phys. 1985, 82, 284.

(29) Jensen, V. R.; Børve, K. J. J. Comput. Chem. 1998, 19, 947.

(30) Frisch, M. J.; Trucks, G. W.; Schlegel, H. B.; Scuseria, G. E.; Robb, M. A.;

Cheeseman, J. R.; Zakrzewski, V. G.; Montgomery, J., J. A.; Stratmann, R. E.; Burant, J. C.; Dapprich, S.; Millam, J. M.; Daniels, A. D.; Kudin, K. N.; Strain, M. C.; Farkas, O.; Tomasi, J.; Barone, V.; Cossi, M.; Cammi, R.; Mennucci, B.; Pomelli, C.; Adamo, C.; Clifford, S.; Ochterski, J.; Petersson, G. A.; Ayala, P. Y.; Cui, Q.; Morokuma, K.; Malick, D. K.; Rabuck, A. D.; Raghavachari, K.; Foresman, J. B.; Cioslowski, J.; Ortiz, J. V.; Baboul, A. G.;

Stefanov, B. B.; Liu, G.; Liashenko, A.; Piskorz, P.; Komaromi, I.; Gomperts, R.; Martin, R. L.; Fox, D. J.; Keith, T.; Al-Laham, M. A.; Peng, C. Y.; Nanayakkara, A.; Gonzalez, C.; Challacombe, M.; Gill, P. M. W.; Johnson, B.; Chen, W.; Wong, M. W.; Andres, J. L.; 
Gonzalez, C.; Head-Gordon, M.; Replogle, E. S.; Pople, J. A. Gaussian 98, Revision A.9; Gaussian, Inc.: Pittsburgh PA, 1998.

(31) Marsal, P.; Roche, M.; Tordo, P.; Claire, P. D. J. Phys. Chem. A 1999, 103, 2899.

(32) Moore, C. E. Atomic Energy Levels; US Government Printing Office: Washington, DC, 1952; Vol. Vols. I-III.

(33) Gundertofte, K.; Liljefors, T.; Norrby, P. J. Comput. Chem. 1996, 17, 429.

(34) Liljefors, T. G., K.; Norrby, P.-O.; Pettersson, I. In Computational Medicinal Chemistry and Drug Discovery; Bultinck, P., Ed.; Marcel Dekker: New York, 2003, in press.

(35) Pratt, D. A.; de Heer, M. I.; Mulder, P.; Ingold, K. U. J. Am. Chem. Soc. 2001, 123, 5518.

(36) Fischer, H. J. Polym. Sci., Part A: Polym. Chem. 1999, 37, 1885.

(37) Matyjaszewski, K.; Patten, T. E.; Xia, J. J. Am. Chem. Soc. 1997, 119, 674.

(38) Pyun, J.; Jia, S.; Kowalewski, T.; Patterson, G. D.; Matyjaszewski, K. Macromolecules 2003, 36, 5094.

(39) Kajiwara, A.; Matyjaszewski, K. Macromol. Rapid Commun. 1998, 19, 319.

(40) Kajiwara, A.; Matyjaszewski, K.; Kamachi, M. Macromolecules 1998, 31, 5695.

(41) Wang, J.-L.; Grimaud, T.; Matyjaszewski, K. Macromolecules 1997, 30, 6507.

(42) Davis, K.; Paik, H.-j.; Matyjaszewski, K. Macromolecules 1999, 32, 1767.

(43) Fischer, H. Chem. Rev. 2001, 101, 3581.

(44) Fischer, H.; Henning, P. Acc. Chem. Res. 1987, 20, 200.

(45) Fischer, H.; Radom, L. Angew. Chem., Int. Ed. 2001, 40, 1340.

(46) Zetterlund, P. B.; Busfield, W. K.; Jenkins, I. D. Macromolecules 1999, 32, 8041.

(47) Matyjaszewski, K.; Wang, J.-L.; Grimaud, T.; Shipp, D. A. Macromolecules 1998, 31, 1527.

(48) Matyjaszewski, K.; Jo, S. M.; Paik, H.-j.; Shipp, D. A. Macromolecules 1999, 32 , 6431.

(49) Matyjaszewski, K. unpublished data.

(50) Percec, V.; Popov, A. V.; Ramirez-Castillo, E.; Monteiro, M.; Barboiu, B.; Weichold, O.; Asandei, A. D.; Mitchell, C. M. J. Am. Chem. Soc. 2002, 124, 4940.

(51) Matyjaszewski, K.; Gaynor, S. G.; Coca, S., 9840415, 1998

(52) Wootthikanokkhan, J.; Peesan, M.; Phinyocheep, P. Eur. Polym. J. 2001, 37, 2063.

(53) Nakagawa, Y.; Matyjaszewski, K. Polym. J. 1998, 30, 138.

(54) Wang, J.-S.; Matyjaszewski, K. Macromolecules 1995, 28, 7901.

(55) Percec, V.; Barboiu, B.; Neumann, A.; Ronda Macromolecules 1996, 29, 3665.

(56) Beuermann, S.; Buback, M. Prog. Pol. Sci. 2002, 27, 191.

(57) Shipp, D. A.; Wang, J.-L.; Matyjaszewski, K. Macromolecules 1998, 31, 8005.

(58) Matyjaszewski, K.; Shipp, D. A.; McMurtry, G. P.; Gaynor, S. G.; Pakula, T. J. Polym. Sci., Part A: Polym. Chem. 2000, 38, 2023.

(59) Matyjaszewski, K.; Shipp, D. A.; Wang, J.-L.; Grimaud, T.; Patten, T. E. Macromolecules 1998, 31, 6836. 